\title{
NGHIÊN CỨU SỰ BIẾN ĐỔI HUYẾT ÁP TRONG QUÁ TRÌNH LỌC MÁU Ở BỂNH NHÂN CHAYY THÂ̂N NHÂN TẠO CHU KỲ
}

\section{TÓM TẮT}

Mục tiêu nghiên cứu: Đánh giá tỷ lệ biến đổi huyêt áp trong quá trình lọc máu ở bệnh nhân chạy thận nhân tạo chu kỳ tại bệnh viện đa khoa 115 Nghệ An. Phương pháp nghiên cứu: nghiên cứu mô tả cắt ngang được thực hiện trên 119 bệnh nhân đang chạy thận nhẩn tạo chu kỳ. Kết quả: Tỷ lệ biến đổi huyết áp trong cuộc lọc máu không phải là hiếm gặp. Qua 714 lần lọc trên 119 bệnh nhân cho ta thây có $20,2 \%$ ca lọc máu có tăng huyết áp và $15,8 \%$ ca lọc có hạ huyết áp. Thời điểm hạ huyết áp hay gặp ở giờ thứ 3 của buổi lọc máu với tỉ lệ cao nhất là 42,5\%. Thời điểm tăng huyết áp hay xảy ra vào giờ đâu của buổi lọc với tỉ lệ cao nhất là 38,9\%. Kết luận : Biến đổi HA có thể xảy ra bất kỳ thời điểm nào trong ca lọc trong đó hạ HA hay xảy ra vào giờ thứ 3 và tăng HA hay xảy ra vào giờ đầu của ca lọc.

Tư khóa: Biến đổi huyết áp, chạy thận nhân tạo chu kỳ.

\section{SUMMARY \\ STUDYING THE BLOOD PRESSURE \\ CHANGES DURING DIALYSIS IN HEMODIALYSIS PATIENTS}

Objectives of the study: To evaluate the rate of changes in blood pressure during dialysis in hemodialysis patients at 115 Nghe An General Hospital. Methods: cross-sectional descriptive studies were performed on 119 patients on dialysis. Results: The rate of change in blood pressure during dialysis is not uncommon. Through 714 filtration times in 119 patients showed that $20,2 \%$ of dialysis patients had hypertension and $15,8 \%$ of dialysis patients had hypotension. The most common time for lowering blood pressure is the 3rd hour after dialysis, accounting for $42.5 \%$. The most common time of hypertension is the 1st hour after dialysis, accounting for $38,9 \%$. Conclusion: Blood pressure chanqe can occur at any time in the dialysis case, in which the hypotension occurs at the 3rd hour and the hypertension occurs at the first hour of the dialysis.

Key words: Changes in blood pressure, hemodialysis

\section{I. ĐẶT VẤN ĐỀ}

Hiện nay trên toàn thế giới ước tính có khoảng 2 triệu người mắc bệnh thận mạn giai

*Trường Đại Hoc Y Khoa Vinh

Chịu trách nhiệm chính: Nguyễn Văn Tuấn

Email: tuanminh1975@gmail.com

Ngày nhận bài: 4.01.2021

Ngày phản biên khoa hoc: 26.2.2021

Ngày duyệt bài: 4.3.2021
Nguyễn Văn Tuấn*, Nguyễn Thị Mỹ Thành*

đoạn cuối và số bệnh nhân được chẩn đoán mắc bênh này tiếp tục tăng ở mức $5-7 \%$ mỗi năm. Điều trị đối với bệnh thận mạn giai đoạn cuối có 3 phương pháp: Ghép thận, lọc màng bụng và thận nhân tao. Trong đó lọc máu chu kỳ chiếm tỷ lệ $90 \%$ tổng số bệnh nhân lọc máu (bao gồm thận nhân tạo theo chu kỳ và lọc màng bụng) [3].

Kỹ thuât lọc máu cũng như máy móc thiết bi đã có nhiểu tiến bộ đáng kể giúp cải thiện tỷ lệ sống sót cho bệnh nhân, kéo dài tuổi thọ cho bênh nhân cũng như chất lượng sống của bệnh nhân. Mặc dù đã có nhiều tiến bộ đáng kể, nhưng tỷ lệ tử vong ở bệnh nhân mắc bệnh thận mạn giai đoạn cuối vẫn còn cao, vì có nhiều nguy cơ mắc bệnh tim mạch cao hơn so với dân số nói chung. Khoảng $50 \%$ số ca tử vong của bệnh thận mạn giai đoạn cuối do nguyên nhân tim mạch [8]. Các biến cố tim mạch hay xảy ra trong quá trình lọc máu được cho do biến đổi huyết áp trong cuộc lọc, bao gồm ha huyết áp chiếm $20-40 \%$, và tăng huyết áp chiểm khoảng $15 \%$ tổng số ca lọc máu theo chu kỳ [7]. Biến đổi huyết áp là một trong các nguyên nhân gây tử vong ở bệnh nhân bệnh thận mạn giai đoạn cuối.

Xuất phát từ vấn đề trền, chúng tôi tiến hành nghiên cứu đề tài này với mục tiêu: Đánh giá biến đổi huyết áp trong quá trinh lọ máu ở bênh nhân bệnh thận mạn giai đoạn cuối chạy thận nhân tạo chu kỳ.

\section{II. ĐỐI TƯƠNG VÀ PHƯƠNG PHÁP NGHIÊN CỨU}

\section{1. Đối tượng nghiên cứu}

1.1. Đối tượng. 119 bênh nhân bênh thận mạn giai đoạn cuối, điều trị thay thế thận bằng lọc máu chu kỳ tại Khoa thận nhân tạo - Bệnh viện đa khoa 115 Nghệ An.

\subsection{Tiêu chuẩn lựa chọn.}

- Tuổi và giới: Bệnh nhân từ 16 tuổi trở lên, thuộc cả 2 giới nam và nữ. Bệnh nhân được chẩn đoán bệnh thận mạn giai đoạn cuối - theo phân loai của KDIGO 2012, điều trị thận nhân tạo chu kỳ và điều trị 3 lần/1 tuần.

- Bệnh nhân đồng ý tham gia nghiên cứu.

1.3. Tiêu chuẩn loại trừ:

- Bệnh nhân đang có bệnh lí cấp tính: nhiễm khuẩn, nhồi máu cơ tim cấp, đột quỵ não. Bệnh nhân suy tim nặng, rối loạn nhịp tim nặng: rung nhĩ, block - nhĩ thất độ III... 
- Bệnh nhân từ chối tham gia nghiên cứu.

2. Phương pháp nghiên cứu

2.1. Thiết kế nghiên cứu: Nghiên cứu mô tả cắt ngang.

\subsection{Phương pháp tiến hành.}

2.2.1. Chuân bị người bệnh. Người bệnh đến lọc máu được hỏi tiền sử, khám lâm sàng, cân nặng trước và sau khi lọc máu. Đo huyết áp vào các thời điểm: đo trước khi lọc máu 10 phút, trong khi lọc máu đo huyết áp định kỳ tại các thời điểm 60,120, 180 phút, sau loc 10 phút và bất kỳ thời điểm nào có các triệu chứng lâm sàng của biến đổi huyết áp.

\subsubsection{Kỹ thuật tiến hành:}

- Kỹ thuật lọc máu: tiến hành lọc máu chu kỳ theo quy chuẩn của Bộ Y Tế Việt Nam năm 2018.

- Kỹ thuật đo huyết áp:

+ Chuẩn bị bệnh nhân: để bệnh nhân nằm trên giường thận nhân tạo, cởi bỏ quần áo chặt, bộc lộ cánh tay bên không có shunt tay, để tay thả lỏng, không nói chuyện trong khi đo.

+ Dụng cụ: sử dụng huyết áp kế đồng hồ.

+ Cách đo và ghi nhận giá trị HA: dùng băng quấn tay đạt tiêu chuẩn. Băng quấn đă̆t ngang mức tim, mép dưới băng quấn trên nếp khuỷu tay $3 \mathrm{~cm}$. Đo 2 lần, cách nhau ít nhất 2 phút, lấy trị số trung bình của 2 lần đo.

\section{Các tiêu chuẩn đánh giá}

3.1. Tiêu chuẩn đánh giá giai đoạn bệnh thận mạn. Chẩn đoán giai đoạn bệnh thận mạn dựa trên mức lọc câu thận theo KDIGO năm 2012.

3.2. Tiêu chuẩn đánh giá biến đổi huyết áp trong cuộc lọc máu:

- Theo K/DOQI, hạ huyết áp là giảm huyết áp tâm thu $\geq 20 \mathrm{mmHg}$ hoặc giảm huyết áp động mạch trung bình $10 \mathrm{mmHg}$ so với trước cuộc lọc kèm với các biểu hiện lâm sàng: hoa mắt, chóng mặt, buồn nôn, nôn, mệt, ngất xỉu...

- Tăng huyết áp trong ca lọc máu:

+ Huyết áp trung bình tăng $\geq 15 \mathrm{mmHg}$ trong ca lọc máu hoặc ngay sau khi kết thúc lọc máu so với huyết áp ngay trước khi bắt đầu lọc.

3.3. Phương pháp xử lý số liệu. Các số liệu thu được nhập vào phần mềm Ecxel xử lý theo phương pháp thống kê y học sử dụng phần mềm SPSS 20.0.

\section{KẾT QUẢ NGHIÊN CỨU VÀ BÀN LUẬN}

4.1. Đặc điểm chung của đối tượng nghiên cứu

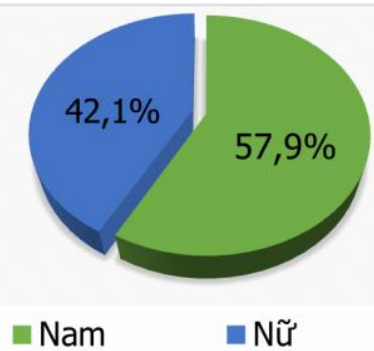

Biểu đồ 1. Phân bố bệnh nhân theo giới tính.

Nhận xét: Nhóm bệnh nhân nghiên cứu có tỷ lệ nam chiếm $57,9 \%$, nữ giới chiếm $42,1 \%$.

Bảng 1. Đặc điêm chung của đối tượng nghiên cứu.

\begin{tabular}{|c|c|c|c|}
\hline Chỉ số & $\mathbf{x} \pm$ SD & $\mathbf{n}$ & $\mathbf{\%}$ \\
\hline Nhóm tuối & & & \\
$<50$ & $46,75 \pm$ & 79 & 60,5 \\
$>50$ & 15,06 & 47 & 39,5 \\
\cline { 1 - 1 } Tống & & $\mathbf{1 1 9}$ & $\mathbf{1 0 0}$ \\
\hline $\begin{array}{c}\text { Thời gian loc máu } \\
\text { chu kỳ (năm) } \\
\text { < } 1 \text { năm }\end{array}$ & & & \\
$1-3$ năm & $3,96 \pm$ & 21 & 17,6 \\
3- 5 năm & 2,99 & 33 & 33,6 \\
> 5 năm & & 25 & 21,1 \\
\hline Tống & & 119 & 100 \\
\hline
\end{tabular}

Nhận xét: Tuối trung bình của nhóm bệnh nhân nghiên cứu là $46,75 \pm 15,06$ tuổi, tuổi thấp nhất là 19 tuổi và tuổi cao nhất là 75 tuổi, nhóm tuổi dưới 50 là độ tuổi chủ yếu ở bệnh nhân lọc máu chiếm $60,5 \%$. Thời gian lọc máu $1-3$ năm chiếm tỷ lệ cao nhất là 33,6\% và có thời gian lọc máu trung bình là $3,96 \pm 2,99$ năm.

4.2. Sự biến đổi huyêt áp trong ca lọc máu.

Bảng 2. Tỷ lệ biến đổi huyêt áp trong ca loc máu

\begin{tabular}{|c|c|c|}
\hline $\begin{array}{c}\text { Tình trang } \\
\text { biến đổi HA }\end{array}$ & $\begin{array}{c}\text { Số ca lọc } \\
\text { máu }\end{array}$ & $\begin{array}{c}\text { Tỷ lệ } \\
\text { \%o }\end{array}$ \\
\hline Tăng HA & 144 & 20,2 \\
\hline Hạ HA & 113 & 15,8 \\
\hline Không biến đối HA & 457 & 64,0 \\
\hline Tống & $\mathbf{7 1 4}$ & $\mathbf{1 0 0}$ \\
\hline
\end{tabular}

Nhận xét: Qua 714 lần lọc máu của 119 bệnh nhân cho thấy có $20,2 \%$ ca lọc có tăng huyết áp và $15,8 \%$ ca lọc có hạ huyết áp.

Bảng 3. Thời điểm biến đổi huyết áp trong cuộc lọc máu.

\begin{tabular}{|c|c|c|c|c|}
\hline \multirow{2}{*}{$\begin{array}{c}\text { Thời điể́m } \\
\text { biến đổi HA }\end{array}$} & \multicolumn{2}{|c|}{ Tụt HA } & \multicolumn{2}{c|}{ Tăng HA } \\
\cline { 2 - 5 } & Số lần LM & Tỷ lệ (\%) & Số lần LM & Tỷ lệ(\%) \\
\hline Giờ đâuu & 15 & 13,3 & 56 & 38,9 \\
\hline Giờ thứ 2 & 23 & 20,4 & 24 & 16,7 \\
\hline
\end{tabular}




\begin{tabular}{|c|c|c|c|c|}
\hline Giờ thứ 3 & 48 & 42,5 & 48 & 33,3 \\
\hline Sau lọc & 27 & 23,8 & 16 & 11,1 \\
\hline Tống & $\mathbf{1 1 3}$ & $\mathbf{1 0 0}$ & $\mathbf{1 4 4}$ & $\mathbf{1 0 0}$ \\
\hline
\end{tabular}

Nhận xét: Thời điếm hạ HA xảy ra nhiều nhất vào giờ thứ 3 với 48 lần lọc chiếm 42,5\%, và sau lọc chiếm $23,8 \%$. Đối với thời điểm bắt đầu xuất hiện tăng huyết áp nhiều nhất là giờ đâu với tỷ lệ $38,9 \%$, giờ thứ 3 và giờ thứ 2 là $33,3 \%$ và $16,7 \%$.

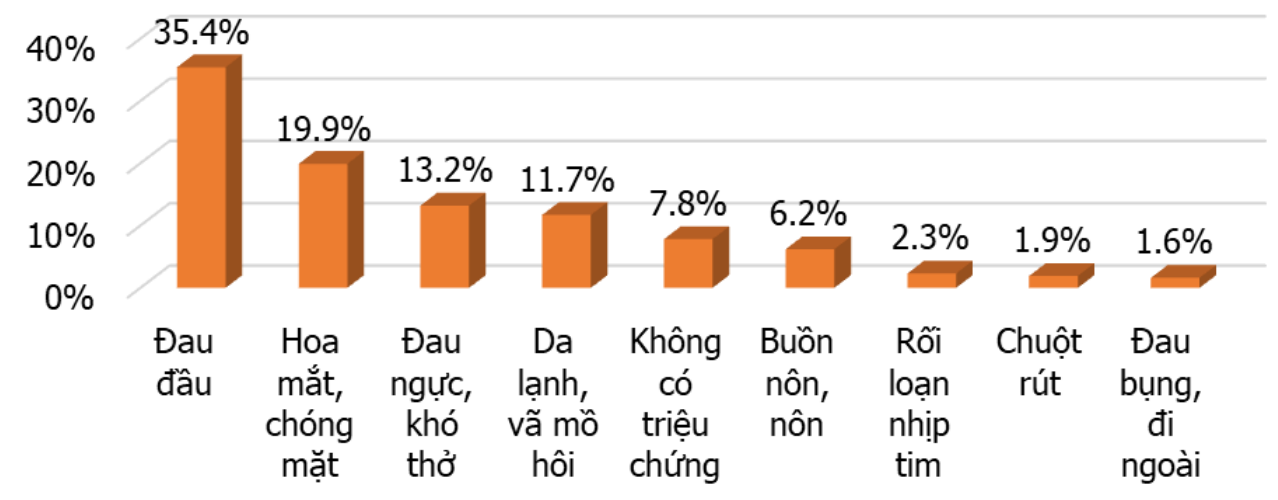

Biểu đồ 2. Các triệu chứng lâm sàng đi kèm biến đổi HA.

Nhận xét: Triệu chứng lâm sàng hay gặp trong các ca lọc có biến đổi huyết áp nhất là đau đầu chiếm 35,4\%, tiếp theo là triêu chứng hoa mắt chóng mặt chiếm 19,9\%.

Bảng 5. So sánh trị số huyêt áp tâm thu trung bình ở các giờ lọc trong các ca lọc có biến đổi HA.

\begin{tabular}{|c|c|c|c|c|}
\hline Giờ lọc & Hạ HA & $\mathbf{p}$ & Tăng HA & $\mathbf{p}$ \\
\hline Giờ đầu (1) & $140,13 \pm 21,53$ & \multirow{4}{*}{$\begin{array}{l}\mathrm{p}_{1-2}<0,05 \\
\mathrm{p}_{1-3}<0,05 \\
\mathrm{p}_{1-4}<0,05 \\
\mathrm{p}_{2-3}<0,05 \\
\mathrm{p}_{2-4}<0,05 \\
\mathrm{p}_{3-4}>0,05\end{array}$} & $150,21 \pm 17,69$ & \multirow{4}{*}{$\begin{array}{l}\mathrm{p}_{1-3}<0,05, \\
\mathrm{p}_{2-3}<0,05, \\
\mathrm{p}_{2-4}<0,05 \\
\mathrm{p}_{3-4}<0,05 \\
\mathrm{p}_{1-2}>0,05 \\
\mathrm{p}_{1-4}>0,05\end{array}$} \\
\hline Giờ thứ 2 (2) & $136,64 \pm 21,17$ & & $149,06 \pm 14,39$ & \\
\hline Giờ thứ $3(3)$ & $132,21 \pm 19,21$ & & $157,05 \pm 15,01$ & \\
\hline Sau Ic & 130,13 & & $\pm 11,41$ & \\
\hline
\end{tabular}

Nhân xét: Chỉ số HATT ở giờ thứ 3 và sau lọc thường thấp hơn so với giờ đầu và giờ thứ 2 . Sự khác biệt có ý nghĩa thống kê $\mathrm{p}<0,05$.

Bảng 6. So sánh trị số huyêt áp trung bình ở các giờ lọc trong các ca lọc có biến đổi HA

\begin{tabular}{|c|c|c|c|c|}
\hline Giờ lọc & Hạ HA & $\mathbf{p}$ & Tăng HA & \multirow{5}{*}{$\begin{array}{l}\mathrm{p}_{1-3}<0,05 \\
\mathrm{p}_{2-3}<0,05 \\
\mathrm{p}_{3-4}<0,05 \\
\mathrm{p}_{1-2}>0,05 \\
\mathrm{p}_{2-4}>0,05 \\
\mathrm{p}_{1-4}>0,05\end{array}$} \\
\hline Giờ đầu (1) & $100,43 \pm 13,78$ & \multirow{4}{*}{$\begin{array}{l}\mathrm{p}_{1-2}<0,05 \\
\mathrm{p}_{1-3}<0,05 \\
\mathrm{p}_{1-4}<0,05 \\
\mathrm{p}_{2-3}<0,05 \\
\mathrm{p}_{2-4}<0,05 \\
\mathrm{p}_{3-4}>0,05\end{array}$} & $108,03 \pm 10,07$ & \\
\hline Giờ thứ 2 (2) & $98,02 \pm 14,04$ & & $106,91 \pm 9,06$ & \\
\hline Giờ thứ 3 (3) & $94,84 \pm 12,78$ & & $112,09 \pm 8,85$ & \\
\hline Sau lọc (4) & $93,88 \pm$ & & $108,29 \pm 6,95$ & \\
\hline
\end{tabular}

Nhân xét: Chỉ số HATB ở giờ thứ 3 và sau lọc thường thấp hơn so với giờ đầu và giờ thứ 2 . Sự khác biệt có ý nghĩa thống kê $\mathrm{p}<0,05$.

\section{BÀN LUẬN}

Tuổi trung bình của nhóm bệnh nhân nghiên cứu là 46,75 $\pm 15,06$ tuổi, tuổi thấp nhất là 19 tuổi và tuổi cao nhất là 75 tuổi, nhóm tuổi dưới 50 là độ tuổi chủ yếu ở bệnh nhân lọc máu chiếm $60,5 \%$. Thời gian lọc máu 1 - 3 năm chiếm tỷ lệ cao nhất là $33,6 \%$ và có thời gian lọc máu trung bình là 3,96 $\pm 2,99$ năm.

Kết quả nghiên cứu chúng tôi qua 714 lần lọc máu của 119 bệnh nhân cho thây có $20,2 \%$ ca lọc có tăng huyết áp và $15,8 \%$ ca lọc có hạ huyết áp. Nghiên cứu của tác giả Đỗ Văn Tùng qua 560 lần lọc thấy $10,9 \%$ ca lọc có THA và tỷ lệ HHA là $12 \%$ [2]. Nghiên cứu của tác Nguyễn Văn Ngọc khảo sát tình trạng tăng huyết áp ở bệnh nhân TNTCK với 1001 ca lọc ở Bệnh viện hữu nghị Việt Đức thấy có 18,5\% ca lọc có THA [1]. Nghiên cứu của chúng tôi có tỷ lể biến đổi HA cao hơn các nghiên cứu trong nước, nhưng so với các nghiên cứu nước ngoài thì tỷ lệ biến 
đổi HA của chúng tôi thấp hơn. Antonio Santoro và cộng sự nghiên cứu ở 36 bệnh nhân với 1536 cuộc lọc được tiến hành ở 10 trung tâm lọc máu lớn ở Italia cho thây tỉ lê HHA khoảng $23,5 \%$ đến $33,5 \%$. Van Buren và cộng sự nghiên cứu trên 22955 ca loc thân nhân tạo trên 362 bênh nhân thấy có $21,3 \%$ các ca lọc có THA (với tiêu chuẩn chẩn đoán HATT tăng trên $10 \mathrm{mmHg}$ từ trước đến sau chạy thận nhân tạo) [4].

Dựa vào kết quả bảng 3 cho ta thấy, thời điểm ha $\mathrm{HA}$ xảy ra nhiều nhất vào giờ thứ 3 với 48 lần lọc chiếm $42,5 \%$, và sau lọc chiếm 23,8\%. Nghiên cứu của Cù Tuyết Anh hạ huyết áp hay xảy ra nhiều nhất trong 60 phút đầu chiếm $36,9 \%$, tỷ lê này ở giờ thứ 4 là $27,6 \%$.

Đối với thời điểm bắt đầu xuất hiện tăng huyết áp nhiều nhất là giờ đầu với tỷ lệ $38,9 \%$, giờ thứ 3 và giờ thứ 2 là $33,3 \%$ và $16,7 \%$. So với nghiên cứu của tác giả Nguyễn Văn Ngọc thì tỷ lệ THA cao nhất vào giờ đầu chiếm $35,7 \%$, giờ thứ 3 chiếm chiếm tỷ lệ $31,4 \%$ [1]. Như vậy, biến đổi huyết áp có thể xảy ra ở bất kỳ thời điểm nào trong buổi lọc máu. Do vậy cán bộ nhân viên y tế cần theo dõi sát người bệnh từ lúc bắt đầu lọc máu cho đến khi kết thúc, nhằm phát hiện sớm các dấu hiệu biến đổi huyết áp. Theo bảng 5 và bảng 6 , tỷ lẹ ha huyết áp trị số HATB và HATT trung bình ở giờ thứ 3 và sau loc thường thấp hơn so với giờ đâu và giờ thứ 2 . Sự khác biệt có ý nghĩa thống kê $p<0,05$.

Đối với nhóm bệnh nhân tăng huyết áp, về HATT trung bình kết quả nghiên cứu cho thây HATT trung bình tăng cao vào giờ thứ $3(157,05$ $\pm 15,01 \mathrm{mmHg})$ và sau lọc $(152,53 \pm 11,41$ $\mathrm{mmHg}$ ). Cao hơn HATT trung bình giờ đầu $(150,21 \pm 17,69 \mathrm{mmHg})$ và giờ thứ $2(149,06 \pm$ $14,39 \mathrm{mmHg})$, nhưng chỉ sự khác biệt huyết áp ở giờ thứ 3 có ý nghĩa thống kê với các giờ còn lại.

Kết quả này cũng tương tự như kết quả nghiên cứu của tác giả Nguyền Văn Ngọc HATT trung bình cao nhất vào giờ $3(155,89 \pm 20,37$ $\mathrm{mmHg}$ ) so với các giờ khác [1].

Theo kết quả nghiên cứu của tác giả Chou và công sự thì huyết áp động mạch trung bình bắt đầu tăng trong giờ đâu tiên sau khi bắt đầu lọc và tăng cao nhất ở giờ thứ 3 và cuối giờ tăng ít hơn [5].

Giờ thứ 3 khi mà tác dụng siêu lọc được biểu hiện, bệnh nhân được rút một lượng nước rất lớn làm thay đổi thể tích trong lòng mạch và khoảng kẽ, cơ thể sẽ có một quá trình điều chỉnh lại sự thay đổi này, đó là kéo nước từ khoảng kẽ vào lòng mạch, các rối loạn trong quá trình này có thể gây nên tăng huyết áp. Bên cạnh đó một số thuốc HHA được loại bỏ một phần hay hoàn toàn trong quá trình chạy thận nhân tạo như thuốc ức chế men chuyển và chẹn beta là một yếu tố thúc đẩy tăng huyết áp trong cuộc lọc [6].

Về huyết áp trung bình cũng tương tự huyết áp tâm thu trung bình, huyết áp trung bình tăng cao nhất vào giờ thứ 3 và thứ 4 . Như vây qua trên ta thây cần có hệ thống theo dõi và giám sát huyết áp của bệnh nhân, đặc biệt là vào các giờ gần cuối ca.

\section{KẾT LUÂN}

Qua nghiên cứu sự biến đổi HA ở 119 bênh nhân đang chạy thận nhân tạo chu kỳ tại Bệnh viện đa khoa 115 Nghệ An chúng tôi đưa ra kết luận sau:

- Tỷ lệ hạ huyết áp chiếm 15,8\%, tỷ lệ tăng huyết áp chiếm $20,2 \%$ trong ca lọc máu.

- Thời điểm hay xảy ra hạ huyết áp vào giờ thứ 3 và tăng huyết áp hay xảy ra vào giờ đâu của ca loc.

- Trị số HATT trung bình và HATB ở giờ thứ 3 và sau lọc ở nhóm $\mathrm{BN}$ biến đổi $\mathrm{HA}$ thường hay biến đổi nhiêu hơn so với giờ đầu và giờ thứ 2 .

\section{TÀI LIÊU THAM KHẢO}

1. Nguyễn Văn Ngọc (2015), Khảo sát tình trạng tăng huyết áp trong ca lọc máu ở bệnh nhân thâan nhân tạo chu kỳ tại bệnh viện hữu nghị Việt Đức, Luận vằn thạc sỹ y học, trường đai học Y Hà Nội.

2. Đố văn Tùng (2010), Nghiên cứu biến chứng tự huyết áp trong lọc máu chu kỳ ở bệnh nhân suy thận mạn giai đoạn cuối tại bệnh viện trung ương đa khoa Thái Nguyên, Luận văn thạc sỹ y học, trường đại học y khoa Thái Nguyên.

3. Bernadette Thomas, Sarah Wulf,Boris Bikbov et at (2015), Maintenance Dialysis throughout the World in Years 1990 and 2010, J Am Soc Nephrol; 26(11): 2621-2633.

4. Catherine Kim Peter N. Van Buren, et al (2012), The prevalence of persistent intradialytic hypertension in a hemodialysis population with extended follow-up, Int J Artif Organs 35 (12): 1031-1038.

5. Chou KP, et al, Physiological changes during hemodialysis in patients with intradialysis hypertension, Kidney International 2006;69,18331838.

6. National Kidney Foundation (2005), K/DOQI Clinical Practice Guidelines for cardiovascular disease in dialysis patients, Am J Kidney Dis; 45:s49-s59.

7. Jula K. Inrig (2010), Intradialytic Hypertension: A Less-Recognized Cardiovascular Complication of Hemodialysis ,Am J Kidney Dis; 55(3): 580-589. doi:10.1053/j.ajkd.2009.08.013.

8. Rosario Cianci, Silvia Lai, Laura Fuiano et al, (2009), Hypertension in Hemodialysis. An Overview on Physiopathology and Therapeutic Approach in Adults and Children, The Open Urology \& Nephrology Journal; 2, 11-19. 